\title{
PRODUCTION RATE AND LOT-SIZE DEPENDENT LEAD TIME REDUCTION STRATEGIES IN A SUPPLY CHAIN MODEL WITH STOCHASTIC DEMAND, CONTROLLABLE SETUP COST AND TRADE-CREDIT FINANCING
}

\author{
Monami Das Roy ${ }^{1}$ And Shib SANKar Sana ${ }^{2, *}$
}

\begin{abstract}
This study explores simultaneous reduction strategies of lead time and setup cost in a twostage supply chain model under trade-credit financing. Lead time depends on a variable production rate and lot size. It consists of setup, production, and transportation time which are shortened to reduce lead time. Although double safety factors are considered to avoid stock-out; but still backorders take place as the demand during the lead time is stochastic. Setup cost is reduced by including an extra investment cost. In addition, the vendor offers a fixed credit period to the buyer to settle the account. The objective is to minimize the integrated expected total cost and optimize the order quantity, number of deliveries, setup and transportation time, setup cost, safety factor for the first batch, and the production rate. A multi-variable optimization technique is used for these purposes. Furthermore, a numerical example together with managerial insights is provided for the establishment and applicability of the proposed model. The numerical results show that the introduction of setup cost reduction and trade-credit financing along with lead time reduction is more beneficial by means of integrated expected total cost reduction.
\end{abstract}

Mathematics Subject Classification. 90B05.

Received April 25, 2020. Accepted October 2, 2020.

\section{INTRODUCTION}

In business today, supply chain management has received top priority due to its performance in complicated and competitive market situations. The main target of a supply chain system is to reduce/lower the operational cost by employing various strategies. The aim of this study is also the same. One of the most common practices of lowering the total cost is lead time reduction. On a single side, the reduction of lead time reduces the safety stock and the loss generated for stock-out. On the other side, it helps to provide better customer service. Another way of reducing the system cost is setup cost reduction. It is an effective activity in a production management system for reducing manufacturing expenses, and hence the integrated total cost.

Generally, the buyer has to clear the payment of the ordered quantity whenever he has received it. But modern business strategies are quite different. In some practical situations, the vendor offers a fixed delay period known

Keywords. Supply chain, inventory, stochastic demand, variable production rate, lead time, setup cost reduction, trade-credit.

1 Department of Mathematics, Haldia Government College, Vidyasagar University, Purba Medinipur 721657, West Bengal, India.

2 Principal, Kishore Bharati Bhagini Nivedita College, R. K. Sarani, Behala, Kolkata 700060, India.

*Corresponding author: shib_sankar@yahoo.com 
as the "trade credit" period to make payment of the purchased order lot. Also, the vendor does not charge any penalty or interest for the permitted delayed period for clearing the payment, whereas if the payment remains unsettled at the end of the credit period, then he charges a higher interest rate on the ordered quantity for the non-permitted delayed period. It gives two advantages to the buyer. First, the buyer has not to pay immediately after receiving the ordered lot. Second, he can get the opportunity to earn interest from the sales revenue and the unpaid amount of money. The existence of the credit period permitted to the buyer reduces the stock holding cost of the buyer for the time-span of the credit period. Therefore, the total cost of the buyer is reduced and consequently the integrated system cost is reduced.

\section{LiterATURE REVIEW}

Supply chain management has become an exciting field of research attention. The advantage of the integration, cooperation, and coordination among the members in a supply chain system attracts several researchers to study different aspects of a supply chain system. Some of the significant works in this direction are Wee et al. [50], Hsiao [18], Lin [30], Das Roy et al. [14], Sarkar et al. [41], Khanna et al. [24], Mahapatra et al. [31], among others.

In inventory literature, supply chain models with variable lead time are discussed by many authors $[7,29,43$, 51]; but a few of them have considered lot-size sensitive lead time. Kim and Benton [22] have considered lot-size sensitive lead time to frame a continuous review inventory model. A two-stage supply chain model with lot-size dependent lead time and stochastic demand is addressed by Ben-Daya and Hariga [1]. Lot-size sensitive fuzzy lead time is taken into account by Maiti and Maiti [32] to develop a two-storage inventory model. All the above studies did not consider lead time reduction. Li et al. [28], Uthayakumar and Priyan [48], and Kim and Sarkar [23] have included lead time reduction strategy in their studies. They have assumed a linear lead time crashing cost function to meet the purpose of reducing lead time. Glock [17] has presented a single-vendor-single-buyer supply chain model with backorders where the lead time is assumed to be influenced by lot size, production rate, and/or setup and transportation time. He has established that lead time may be reduced by reducing setup, production, and transportation time. Sarkar et al. [42] have extended Glock's [17] work by including setup and quality control. This study may also be considered as an extension of the work of Glock [17].

In 1986, Porteus [37] had introduced setup cost reduction together with process quality improvement in an inventory model. The reduction of both: lead time and setup cost in an inventory model with shortages is discussed by Ouyang and Chang [34]. Pan and Lo [36] have investigated the learning effect on setup cost reduction, while Tiwari et al. [47] have reduced setup cost together with ordering cost and lead time in an economic lot size model with complete backorders. A two-stage vendor-buyer supply chain model with controllable setup cost and exponential lead time crashing cost is presented by Das Roy [7]. Sarkar [38] has framed a multi-stage production system with random defectives. He has introduced a discrete investment for setup cost control. A discrete capital investment for setup cost reduction is also considered by Tayyab et al. [46] in a multi-stage and multi-item textile production system. Das Roy [8] has incorporated a three-stage multi-item supply chain model with setup cost reduction together with quality and ordering cost control. The authors Sarker and Coates [43], Uthayakumar and Priyan [48], Sarkar and Moon [39], and Kim and Sarkar [23] have also taken setup cost reduction into consideration.

In most of the studies, production rate is considered as a constant (see $[10,11,33,45])$. It is more convenient to consider the production rate as a variable. An economic production lot size (EPLS) inventory model is developed by Khouja and Mehrez [25] where they have assumed a variable production rate. Das Roy et al. [14] have investigated a two-stage integrated supply chain inventory model in which they have considered a variable production rate for an economic manufacturing quantity (EMQ) and Just-in-time (JIT) manufacturing system. They have assumed the unit production cost as a function of production rate, while Glock [17] has studied an integrated vendor-buyer model by introducing the concept of controlling production rate within an upper and lower bound of production rate. Das Roy et al. [15] have determined an optimal production rate for an economic production lot size model (EPLS) for stochastic demand, whereas a markdown policy for an economic 
production quantity (EPQ) model with variable manufacturing rate is presented by Das Roy [5]. Sarkar and Sarkar [40] have considered smart multi-stage biofuel manufacturing system having variable production rate, whereas an autonomation strategy to control work-in-process stocks with a variable production rate and planned backorder is suggested by Dey et al. [16].

Today, supplier prefers to offer credit period to the retailer/buyer for encouraging them to order more. The advantage of offering such a credit period has attracted researchers to investigate inventory models in context with trade-credit financing as well as a permissible delay period. Chen and Kang [3] have presented a trade-credit policy in an integrated supply chain model for imperfect quality items, while supply chain coordination with permissible delay in payment is discussed by Huang et al. [19], where an order-processing time reduction is taken into consideration. They have determined the optimal number of deliveries, delivery interval, and investment cost in order-processing time. Chung and Cardenas-Barron [4] have proposed a simplified solution procedure for a supply chain model having stock-dependent demand. They have assumed deterioration of product and twolevel of trade-credit in their model. An integrated inventory model with the reduction of lead time and setup cost together with permissible delay in payment is investigated by Uthayakumar and Priyan [48]. Saxena et al. [44] have presented a trade-credit policy in a green supply chain model. Das Roy [9] has incorporated a supply chain inventory model for stochastic demand where a trade credit policy together with lead time and ordering cost reduction is introduced. There are a number of renowned authors who have included trade-credit/permissible delay in payments in their model formulation. A few of them are Jaber and Osman [20], Lashgari et al. [26], Pal et al. [35], Kim and Sarkar [23], and Udayakumar et al. [49].

In this article, the author has taken all the strategies considered by Glock [17] to reduce the lead time. In addition, setup cost reduction and trade-credit financing are introduced to lower the integrated expected total cost. For controlling setup cost, an additional cost is taken into consideration which is a logarithmic function of setup cost. Also, a fixed credit period is offered by the vendor to the buyer to clear the payment of the purchased order. The purpose of the present research work is to minimize the integrated expected total cost by optimizing the values of production rate, ordered quantity, setup and transportation time, setup cost, safety factor for the first batch, and the number of deliveries from the vendor to the buyer. The main contribution of this research work is to present a more cost-reduced supply chain system. The contribution of the present work along with the other relevant works are summarized in Table 1.

The whole paper is split into seven sections. Section 1 contains the "Introduction" part, while Section 2 contains the "Literature review". "Notation and assumptions" are stated in Section 3. Sections 4 and 5 respectively describe the "Model framework" and "Solution technique". "Numerical results, comparative study and managerial insights" are presented in Section 6, while Section 7 draws the "Conclusion" of the study.

\section{Notation And ASSUmptions}

All the notation and assumptions are considered to be as same as assumed by Glock [17]. In addition, some new notation and assumptions are introduced as follows.

\subsection{Notation}

\section{(a) Decision variables}

$Q \quad$ Ordered lot size of the vendor (units).

$n \quad$ Number of shipments from the vendor to the buyer (integer).

$t_{S} \quad$ Setup and transportation time.

$\widetilde{c_{S}} \quad$ Setup cost per setup of the vendor (\$/setup).

$k_{1} \quad$ Safety factor for batch 1 .

$P \quad$ Production rate of the vendor (units/time). 
TABLE 1. Contribution of the present and other relevant works.

\begin{tabular}{|c|c|c|c|c|c|c|c|c|}
\hline Authors & $\begin{array}{l}\text { Supply } \\
\text { chain }\end{array}$ & $\begin{array}{l}\text { Stochastic } \\
\text { demand }\end{array}$ & $\begin{array}{l}\text { Lot size } \\
\text { dependent } \\
\text { lead time }\end{array}$ & $\begin{array}{l}\text { Lead time } \\
\text { reduction }\end{array}$ & $\begin{array}{l}\text { Setup cost } \\
\text { reduction }\end{array}$ & $\begin{array}{l}\text { Variable } \\
\text { production } \\
\text { rate }\end{array}$ & Shortage & $\begin{array}{l}\text { Trade- } \\
\text { credit }\end{array}$ \\
\hline $\begin{array}{l}\text { Kim and Benton } \\
{[22]}\end{array}$ & & & $\checkmark$ & & & & $\checkmark$ & \\
\hline $\begin{array}{l}\text { Ouyang and } \\
\text { Chang [34] }\end{array}$ & & $\checkmark$ & & $\checkmark$ & $\checkmark$ & & $\checkmark$ & \\
\hline $\begin{array}{l}\text { Ben-Daya and } \\
\text { Hariga [1] }\end{array}$ & $\checkmark$ & $\checkmark$ & $\checkmark$ & & & & $\checkmark$ & \\
\hline $\begin{array}{l}\text { Maiti and Maiti } \\
\text { [32] }\end{array}$ & & & $\checkmark$ & & & & $\checkmark$ & \\
\hline Pan and Lo [36] & & $\checkmark$ & & $\checkmark$ & $\checkmark$ & & $\checkmark$ & \\
\hline Glock [17] & $\checkmark$ & $\checkmark$ & $\checkmark$ & $\checkmark$ & & $\checkmark$ & $\checkmark$ & \\
\hline $\begin{array}{l}\text { Uthayakumar } \\
\text { and Priyan [48] }\end{array}$ & $\checkmark$ & $\checkmark$ & & $\checkmark$ & $\checkmark$ & & $\checkmark$ & $\checkmark$ \\
\hline $\begin{array}{l}\text { Kim and Sarkar } \\
{[23]}\end{array}$ & $\checkmark$ & $\checkmark$ & & $\checkmark$ & $\checkmark$ & & $\checkmark$ & $\checkmark$ \\
\hline Tiwari et al. [47] & $\checkmark$ & $\checkmark$ & & $\checkmark$ & $\checkmark$ & & $\checkmark$ & \\
\hline Sarkar et al. [42] & $\checkmark$ & $\checkmark$ & $\checkmark$ & $\checkmark$ & $\checkmark$ & $\checkmark$ & $\checkmark$ & \\
\hline Das Roy [9] & $\checkmark$ & $\checkmark$ & & $\checkmark$ & & & & $\checkmark$ \\
\hline Present work & $\checkmark$ & $\checkmark$ & $\checkmark$ & $\checkmark$ & $\checkmark$ & $\checkmark$ & $\checkmark$ & $\checkmark$ \\
\hline
\end{tabular}

\section{(b) Parameters}

$P_{\max } \quad$ Maximum value of $P$ (units/time).

$P_{\min } \quad$ Minimum value of $P$ (units/time).

$a_{1} \quad$ Machine running cost of the vendor per unit time (\$/unit time).

$a_{2} \quad$ Increasing machining cost of the vendor due to one unit increase in production rate (\$/unit time).

$m \quad$ Total number of lead time components (integer).

$c_{0} \quad$ Order costs per order of the buyer $(\$ /$ order $)$.

$c_{S} \quad$ Original setup cost per setup of the vendor (\$/setup).

$c_{T} \quad$ Transportation costs per shipment of the vendor (\$/shipment).

$c_{B} \quad$ Unit purchase price of the buyer (\$/unit).

$c_{B S} \quad$ Unit selling price of the buyer (\$/unit).

$c_{C, i} \quad$ Crashing cost of setup time component $i$, where $i=1,2,3, \ldots, m(\$ /$ setup).

$D \quad$ Rate of demand (units/time).

$t_{T} \quad$ Transportation time of a batch shipment.

$\varepsilon \quad$ Ratio of transportation time $t_{T}$ in setup and transportation time $t_{S}$, i.e. $\varepsilon=t_{T} / t_{S}$.

$h_{b} \quad$ Unit inventory holding cost per unit of time at the buyer (\$/unit/unit time).

$h_{v} \quad$ Unit inventory holding cost per unit of time at the vendor $(\$ /$ unit/unit time).

$k_{2} \quad$ Safety factor for batch $2,3, \ldots, m$.

$\pi \quad$ Unit backorder cost of the buyer (\$/unit).

$S \quad$ Safety stock.

$s_{1} \quad$ Reorder point of the buyer for batch 1 .

$s_{2} \quad$ Reorder point of the buyer for batches $2,3, \ldots, m$. 


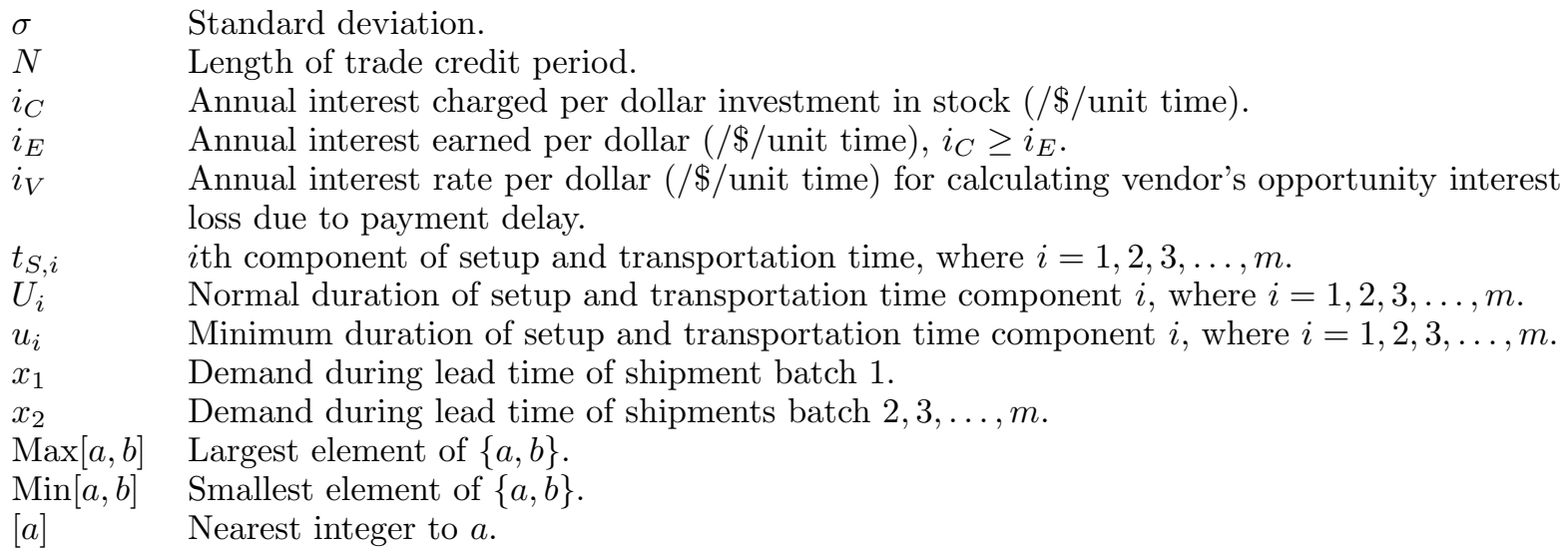

(c) Functions

$\begin{array}{ll}L(P, Q) & \text { Lead time for first batch. } \\ L\left(t_{T}\right) & \text { Lead time for batch } 2 \text { to onwards. } \\ R\left(t_{S}\right) & \text { Crashing costs of } t_{S}(\$ / \text { setup). } \\ c_{P}(P) & \text { Unit production cost function of the vendor }(\$ / \text { unit). } \\ I\left(\widetilde{c_{S}}\right) & \text { Capital investment for setup cost reduction }(\$) . \\ f\left(x_{1}\right) & \text { Probability density function of } x_{1} . \\ f\left(x_{2}\right) & \text { Probability density function of } x_{2} . \\ \operatorname{EIC}\left(Q, \widetilde{c_{S}}, k_{1}, P, t_{S}, n\right) & \text { Integrated expected total cost per unit of time }(\$ / \text { unit time), } \\ & \text { where EIC }=\operatorname{EIC~}\left(Q, \widetilde{c_{S}}, k_{1}, P, t_{S}, n\right) .\end{array}$

\subsection{Assumptions}

The assumptions of the proposed model are as follows.

(1) The vendor manufactures a single type of product. He/she produces and delivers the whole ordered amount of the buyer in a single-setup-multiple-delivery process under a controllable production rate, where the lower bound of production rate is greater than the demand rate of the buyer.

(2) Setup cost reduction is considered to reduce the cost of the vendor, and hence the integrated total cost. The capital investment for reducing setup cost is assumed to be a logarithmic function of setup cost.

(3) Lead time for the first delivery lot is directly proportional to the ordered lot size and the sum of setup, production, and transportation time (see $[21,22]$ ), i.e. $L(P, Q)=t_{S}+p Q$. The lead time demand rate of the buyer follows normal distribution. The probability density function of the lead time demand $x$ is $f(x, D L(P, Q), \sigma \sqrt{L(P, Q)})$ with mean $D L(P, Q)$ and standard deviation $\sigma \sqrt{L(P, Q)}$. The production rate $P>D$, so for shipments of batch $2,3, \ldots, m$, only transportation time $t_{T}$ has to be taken into consideration for calculating lead time because the production of batch $2,3, \ldots, m$ have been completed when the order of the buyer reaches to the vendor (see [18]).

(4) The transportation time $t_{T}$ from the vendor to the buyer is a fraction of the sum of setup and transportation time $t_{S}$, i.e., $t_{T}=\varepsilon t_{S}$. The setup and transportation time of the vendor has $m$ mutually independent components $t_{S, i}$, i.e. $t_{S}=\sum_{i=1}^{m} t_{S, i}$. The $i$ th component has a normal duration $U_{i}$ and a minimum duration $u_{i}$ with a crashing cost per unit time $c_{C, i}, i=1,2,3, \ldots, m$ such that $c_{C, 1} \leq c_{C, 2} \leq \ldots \leq c_{C, m}$. This means the first lead time component has the least crashing cost and the $m$ th lead time component has the highest crashing cost, etc. One component is crashed at a time starting with one that has least $c_{C, i}$ and so on (see [29]). The $i$ th component $t_{S, i} \in\left[u_{i}, U_{i}\right]$. It means each component may be reduced from $U_{i}$ to 
any value within $\left[u_{i}, U_{i}\right]$. The idea of Liao and Shyu [29] and Glock [17] is considered to calculate the setup and transportation time crashing costs $R\left(t_{S}\right)$. According to them, if $t_{S, i}=u_{i}$ for all $i=1,2,3, \ldots, m$ then $t_{S, \min }=\sum_{i=1}^{m} u_{i} \leq t_{S} \leq \sum_{i=1}^{m} U_{i}=t_{S, \max }$. Also, if $t_{S, j}$ be the lead time length with component $1,2,3, \ldots$, $j$ crashed to their minimum duration then $t_{S, j}=\sum_{i=1}^{m} U_{i}-\sum_{i=1}^{j}\left(U_{i}-u_{i}\right)=\sum_{i=j+1}^{m} U_{i}+\sum_{i=1}^{j} u_{i}$ for $j=1,2,3, \ldots, m$ and $R\left(t_{S}\right)=c_{C, j}\left(t_{S, j-1}-t_{S}\right)+\sum_{i=1}^{j-1} c_{C, i}\left(U_{i}-u_{i}\right)$ for a given $t_{S, j}<t_{S} \leq t_{S, j-1}$.

(5) Shortages take place (see $[2,6,12,13,27])$.

(6) Vendor permits a credit period to the buyer for settling his account.

\section{MODEL FRAMEWORK}

The vendor produces the whole ordered lot of size $n Q$ while getting the order from the buyer and ships them into $n$ times each of size $Q$ to the buyer after every $Q / D$ time units. The production rate $P$ is a decision variable and $P \in\left[P_{\min }, P_{\max }\right]$. To assure the sufficient capacity of the vendor for satisfying the demand of the buyer, it is assumed that $P_{\min }>D$. The manufacturer invests an extra cost for reducing his setup cost. The lead time is reduced by reducing setup, production and transportation time. If the buyer requests the vendor to reduce the setup and transportation time, then the additional cost incurred for such reduction is totally transferred to the buyer. On the other hand, the vendor has to bear an extra cost for increasing the production rate as well as shortening the lead time. To encourage the buyer to order more, the vendor offers a fixed credit period $N$ to the buyer. $N$ is less than the reorder interval that means the buyer is permitted to make payment before placing another order. During the credit period, the buyer sells the products and deposits the sales income in an interest-bearing account to earn interest at a rate $i_{E}$. On the other hand, the vendor faces opportunity interest loss at a rate $i_{V}$ during the credit period. Here, $i_{V}=i_{E}$ (see [48]). At the end of this credit period, the buyer pays the purchasing cost to the vendor and starts paying the interest at a rate $i_{C}$ charged to him by the bank from which he had taken a loan for the unpaid purchased cost of the product. The inventory levels of vendor-buyer supply chain over time is shown in Figure 1.

To formulate the proposed model, the expected total cost of the vendor, buyer, and their integrated system are calculated separately in the following subsections.

\subsection{Buyer's expected total cost}

The buyer continuously reviews his inventory stock level and maintain two safety factors. After every cycle time $Q / D$, the buyer orders $Q$ units to the vendor. Buyer's various costs per unit time are as follows.

$$
\text { Ordering cost }=\frac{c_{0} D}{n Q} \text {. }
$$

The average stock of the buyer is $\left(\frac{Q}{2}+S\right)$. So, the inventory holding cost of the buyer is

$$
=h_{b}\left(\frac{Q}{2}+S\right) \text {. }
$$

The backorder amount of first batch is $b\left(s_{1}, L(P, Q)\right)$ and the other subsequent batches are $b\left(s_{2}, L\left(t_{T}\right)\right)$. Therefore, the total backorder cost of the buyer is

$$
\frac{D \pi}{n Q}\left(b\left(s_{1}, L(P, Q)\right)+(n-1) b\left(s_{2}, L\left(t_{T}\right)\right)\right) .
$$

To reduce lead time, the buyer requests the manufacturer to shorten the setup and transportation time $t_{S}$ and bears the extra cost needed for such reduction. Therefore, buyer's crashing cost for reducing $t_{S}$ is

$$
\frac{n D R\left(t_{S}\right)}{n Q} \text {. }
$$



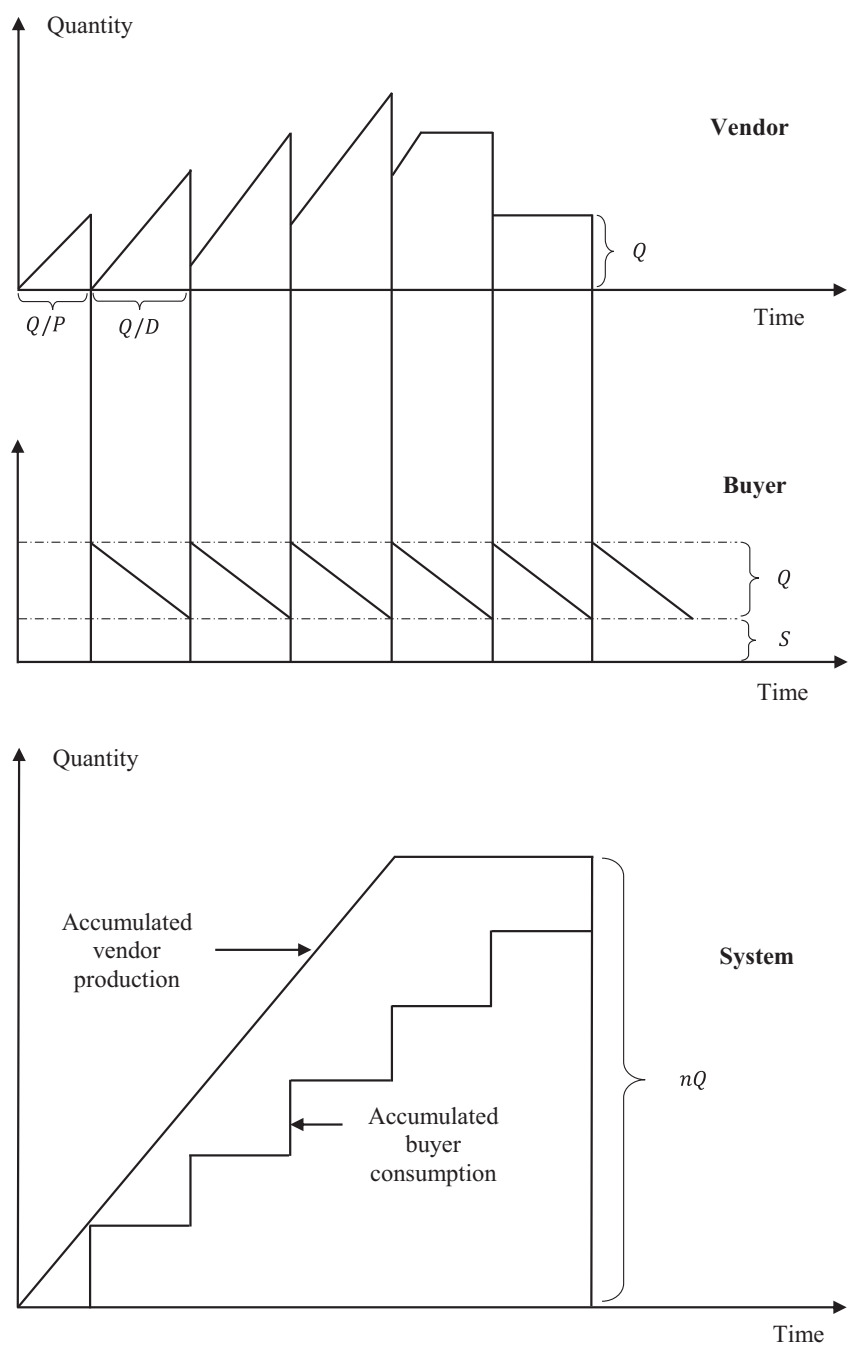

FIGURE 1. Inventory levels of the vendor-buyer supply chain system over time.

The buyer bears the transportation cost and it is

$$
\frac{n D c_{T}}{n Q}
$$

The expected total cost of the buyer per unit of time (see [17]) is as follows

$$
\begin{aligned}
\mathrm{ETC}_{b}= & \left(c_{0}+n c_{T}\right) \frac{D}{n Q}+h_{b}\left(\frac{Q}{2}+S\right) \\
& +\frac{D}{n Q}\left(\pi\left(b\left(s_{1}, L(P, Q)\right)+(n-1) b\left(s_{2}, L\left(t_{T}\right)\right)\right)+n R\left(t_{S}\right)\right)
\end{aligned}
$$

with $b\left(s_{1}, L(P, Q)\right)=\int_{s_{1}}^{\infty}\left(x_{1}-s_{1}\right) f\left(x_{1}\right) \mathrm{d} x_{1}$ and $b\left(s_{2}, L\left(t_{T}\right)\right)=\int_{s_{2}}^{\infty}\left(x_{2}-s_{2}\right) f\left(x_{2}\right) \mathrm{d} x_{2}$. 
The vendor provides a credit period $N>0$ to the buyer to pay the purchase cost of previous order. The buyer sells all goods and keep the sales revenue in an interest-bearing account for the period $[0, N]$. The interest earned by the buyer per unit time on sales revenue is

$$
\frac{c_{B S} i_{E} D^{2} N^{2}}{2 Q}
$$

The buyer has also earned interest on the sales revenue of backordered products. The interest earned by the buyer per unit time on sales revenue of backordered items is

$$
\frac{c_{B S} i_{E} D N}{n Q}\left\{b\left(s_{1}, L(P, Q)\right)+(n-1) b\left(s_{2}, L\left(t_{T}\right)\right)\right\} .
$$

The buyer is charged an interest for the unsold units for the period $[N, Q / D]$. So, the interest charged to the buyer per unit time on unsold stock is

$$
\frac{c_{B} i_{C}(Q-D N)^{2}}{2 Q}
$$

Therefore, the expected total cost of the buyer per unit of time becomes

$$
\begin{aligned}
\mathrm{ETC}_{b}= & \left(c_{0}+n c_{T}\right) \frac{D}{n Q}+h_{b}\left(\frac{Q}{2}+S\right) \\
& +\frac{D}{n Q}\left(\pi\left(b\left(s_{1}, L(P, Q)\right)+(n-1) b\left(s_{2}, L\left(t_{T}\right)\right)\right)+n R\left(t_{S}\right)\right)-\frac{c_{B S} i_{E} D^{2} N^{2}}{2 Q} \\
& -\frac{c_{B S} i_{E} D N}{n Q}\left\{b\left(s_{1}, L(P, Q)\right)+(n-1) b\left(s_{2}, L\left(t_{T}\right)\right)\right\}+\frac{c_{B} i_{C}(Q-D N)^{2}}{2 Q} .
\end{aligned}
$$

\subsection{Vendor's expected total cost}

The vendor manufactures the whole ordered amount in a single setup. His/Her cycle time is $n Q / D$. The setup cos of the vendor is

$$
\frac{\widetilde{c_{S}} D}{n Q} \text {. }
$$

The production run time decreases with the increase in production rate. The unit production cost of the vendor is considered to be as same as considered by Glock [17] and Sarkar et al. [42], which is as follows.

$$
c_{P}(P)=\frac{a_{1}}{P}+a_{2} P \text {. }
$$

The holding cost of the vendor is same as calculate by Glock [17] (see Fig. 1) and it is

$$
=h_{v} \frac{Q}{2}(n(1-D p)-1+2 D p) \text {. }
$$

The expected total cost of the vendor per unit of time as calculated by Glock [17] is

$$
\mathrm{ETC}_{v}=\frac{\widetilde{c_{S}} D}{n Q}+h_{v} \frac{Q}{2}(n(1-D p)-1+2 D p)+D c_{P}(P)
$$

Investment for setup cost reduction

The vendor invests some money $I\left(\widetilde{c_{S}}\right)$ to reduce the setup cost. The concept of Porteus [37], Ouyang and Chang [34], and Das Roy [7] are taken into consideration for setup cost reduction that is

$$
I\left(\widetilde{c_{S}}\right)=A\left(\ln c_{S}-\ln \widetilde{c_{S}}\right)
$$


where $A=\frac{1}{\alpha}, \alpha$ is the percentage decrease in $\widetilde{c_{S}}$ per dollar increase in $I\left(\widetilde{c_{S}}\right)$.

The vendor permits a credit period $N$ to the buyer for clearing his payment. Therefore, the vendor loses an opportunity to earn interest for the period $[0, N]$. The opportunity interest loses by the vendor per unit of time is

$$
c_{B} i_{V} D N
$$

Therefore, the expected total cost of the vendor per unit of time becomes

$$
\begin{aligned}
\mathrm{ETC}_{v}= & \mu A\left(\ln c_{S}-\ln \widetilde{c_{S}}\right)+\frac{\widetilde{c_{S}} D}{n Q}+h_{v} \frac{Q}{2}(n(1-D p)-1+2 D p) \\
& +D c_{P}(P)+c_{B} i_{V} D N,
\end{aligned}
$$

where $\mu$ indicates the annual fractional cost of Vendor's capital investment.

\subsection{Integrated expected total cost}

The integrated expected total cost per unit of time is the sum of $\mathrm{ETC}_{b}$ and $\mathrm{ETC}_{v}$ which can be written as follows.

$$
\begin{aligned}
\mathrm{EIC}= & \frac{D}{n Q}\left[c_{0}+\widetilde{c_{s}}+n c_{T}+\left(\pi-c_{B S} i_{E} N\right)\left\{b\left(s_{1}, L(P, Q)\right)+(n-1) b\left(s_{2}, L\left(t_{T}\right)\right)\right\}\right. \\
& \left.+n R\left(t_{s}\right)+\frac{n D N^{2}}{2}\left(c_{B} i_{C}-c_{B S} i_{E}\right)\right]+\mu A\left(\operatorname{In} c_{s}-\operatorname{In} \widetilde{c_{s}}\right) \\
& +\frac{Q}{2}\left[h_{b}+h_{v}\{n(1-D p)-1+2 D p\}+c_{B} i_{C}\right]+h_{b} S \\
& +D c_{P}(P)+c_{B} D N\left(i_{V}-i_{C}\right) .
\end{aligned}
$$

The lead time demands $x_{1}$ and $x_{2}$ are normally distributed with mean $D L(P, Q)$ and $D L\left(t_{T}\right)$, respectively, and standard deviation $\sigma \sqrt{L(P, Q)}$ and $\sigma \sqrt{L\left(t_{T}\right)}$ respectively as considered by Glock [17]. According to the work of Hsiao [18], the safety stock can be written as

$$
S=k_{1} \sigma \sqrt{L(P, Q)}=k_{1} \sigma \sqrt{t_{S}+p Q} .
$$

The expected amount of shortages for the first batch and for $2,3, \ldots, n$ batches are respectively (see [17])

$$
b\left(s_{1}, L(P, Q)\right)=\int_{s_{1}}^{\infty}\left(x_{1}-s_{1}\right) f\left(x_{1}\right) \mathrm{d} x_{1}=\sigma \sqrt{t_{S}+p Q} \psi\left(k_{1}\right)
$$

and

$$
b\left(s_{2}, L\left(t_{T}\right)\right)=\int_{s_{2}}^{\infty}\left(x_{2}-s_{2}\right) f\left(x_{2}\right) \mathrm{d} x_{2}=\sigma \sqrt{t_{T}} \psi\left(k_{2}\right) .
$$

Here, $\psi\left(k_{i}\right), i=1,2$ are the loss functions and they can be calculated as

$$
\psi\left(k_{i}\right)=\varphi\left(k_{i}\right)-\left[1-F\left(k_{i}\right)\right],
$$

where $\varphi$ is the standard normal probability density function and $F$ is cumulative distribution function of the normal distribution. The complement of the cumulative distribution function is $\bar{F}$ that is $\bar{F}\left(k_{i}\right)=1-F\left(k_{i}\right)$, $i=1,2$.

The safety stock of the buyer as shown in Hsiao [18] can also be written as

$$
S=k_{2} \sigma \sqrt{L\left(t_{T}\right)}=k_{2} \sigma \sqrt{t_{T}} .
$$


From equations (4.6) and (4.10), we get

$$
k_{2}=k_{1} \sqrt{\frac{t_{S}+p Q}{t_{T}}} .
$$

The integrated expected total cost per unit of time can be expressed as

$$
\begin{aligned}
\mathrm{EIC}= & \mu A\left(\ln c_{S}-\ln \widetilde{c_{S}}\right)+\frac{D}{Q}\left[J_{0}(n)+\frac{\widetilde{c_{S}}}{n}\right]+\frac{Q}{2} J_{1}(n, P) \\
& +h_{b} k_{1} \sigma \sqrt{t_{S}+p Q}+D\left(\frac{a_{1}}{P}+a_{2} P\right)+c_{B} D N\left(i_{V}-i_{C}\right) \\
& +\frac{D}{n Q}\left[\sigma\left(\pi-c_{B S} i_{E} N\right)\left\{\sqrt{t_{S}+p Q} \psi\left(k_{1}\right)+(n-1) \sqrt{t_{T}} \psi\left(k_{2}\right)\right\}+n R\left(t_{S}\right)\right],
\end{aligned}
$$

where $J_{0}(n)=\frac{c_{0}}{n}+c_{T}+\frac{D N^{2}}{2}\left(c_{B} i_{C}-c_{B S} i_{E}\right)$ and $J_{1}(n, P)=h_{b}+h_{v}\{n(1-D p)-1+2 D p\}+c_{B} i_{C}$.

The problem can be stated as

$$
\begin{aligned}
& \operatorname{Min} \operatorname{EIC}\left(Q, \widetilde{c_{S}}, k_{1}, P, t_{S}, n\right) \\
& \text { Subject to } 0<\widetilde{c_{S}} \leq c_{S}
\end{aligned}
$$

\section{Solution technique}

To solve the nonlinear problem stated in equation (4.13), first we relax the constraint $0<\widetilde{c_{S}} \leq c_{S}$, which is a common practice in literature (see [7,48], among others), and then obtain the optimal value of $\operatorname{EIC}\left(Q, \widetilde{c_{S}}, k_{1}, P, t_{S}, n\right)$.

With the help of the same arguments as stated by Glock [17], it can be said that $\operatorname{EIC}\left(Q, \widetilde{c_{S}}, k_{1}, P, t_{S}, n\right)$ possesses its minimum value at the end points of the time interval $\left[t_{S, i}, t_{S, i-1}\right]$ (see $[17,29]$ ), and the optimal value of $t_{S}$ can be obtained by testing each possible values of $t_{S}$ when the values of $Q, \widetilde{c_{S}}, k_{1}, P$, and $n$ are given. To find the solution for the other variables, first we take the first order partial derivatives of EIC with respect to $Q, \widetilde{c_{S}}, k_{1}$, and $P$ for a fixed positive integer $n$ and obtain the following

$$
\begin{aligned}
& \frac{\partial \mathrm{EIC}}{\partial Q}=-\frac{D}{Q^{2}}\left[J_{0}(n)+\frac{\widetilde{c_{S}}}{n}+n R\left(t_{S}\right)+\frac{\sigma\left(\pi-c_{B S} i_{E} N\right)}{n}\left\{\sqrt{t_{S}+p Q} \psi\left(k_{1}\right)+(n-1) \sqrt{t_{T}} \psi\left(k_{2}\right)\right\}\right] \\
& +\frac{1}{2}\left[J_{1}(n, P)+\frac{D p \sigma\left(\pi-c_{B S} i_{E} N\right) \psi\left(k_{1}\right)}{n Q \sqrt{t_{S}+p Q}}+\frac{h_{b} k_{1} \sigma p}{2 \sqrt{t_{S}+p Q}}\right] \\
& \frac{\partial \mathrm{EIC}}{\partial \widetilde{c_{S}}}=-\frac{\mu A}{\widetilde{c_{S}}}+\frac{D}{n Q} \\
& \frac{\partial \mathrm{EIC}}{\partial k_{1}}=h_{b} \sigma \sqrt{t_{S}+p Q} \\
& -\frac{D \sigma\left(\pi-c_{B S} i_{E} N\right)}{n Q}\left\{\bar{F}\left(k_{1}\right)+(n-1) \bar{F}\left(k_{1} \sqrt{\frac{t_{S}+p Q}{t_{T}}}\right)\right\} \sqrt{t_{S}+p Q} \\
& \frac{\partial \mathrm{EIC}}{\partial P}=D\left(-\frac{a_{1}}{P^{2}}+a_{2}\right)+\frac{Q h_{v} D}{2 P^{2}}(n-2)-\frac{Q \sigma h_{b} k_{1}}{2 P^{2} \sqrt{t_{S}+p Q}} \\
& -\frac{D \sigma\left(\pi-c_{B S} i_{E} N\right) \psi\left(k_{1}\right)}{2 n P^{2} \sqrt{t_{S}+p Q}} \text {. }
\end{aligned}
$$


To get the optimal values of $Q, \widetilde{c_{S}}, k_{1}$, and $P$ for given values of $n$ and $t_{S}$, equating equations (5.1)-(5.4) equals to zero. After rearranging and simplifying, the values of $Q, \widetilde{c_{S}}, k_{1}$, and $P$ are obtained as follows

$$
\begin{aligned}
Q & =\sqrt{\frac{2 D\left[J_{0}(n)+\frac{\widetilde{c_{S}}}{n}+n R\left(t_{S}\right)+\frac{\sigma\left(\pi-c_{B S} i_{E} N\right)}{n}\left\{\sqrt{t_{S}+p Q} \psi\left(k_{1}\right)+(n-1) \sqrt{t_{T}} \psi\left(k_{2}\right)\right\}\right]}{J_{1}(n, P)+\frac{h_{b} \sigma p}{\sqrt{t_{S}+p Q}}\left\{k_{1}+\frac{\psi\left(k_{1}\right)}{\bar{F}\left(k_{1}\right)+(n-1) \bar{F}\left(k_{1} \sqrt{\left(t_{S}+p Q\right) / t_{T}}\right)}\right\}}} \\
\widetilde{c_{S}} & =\frac{n \mu A Q}{D} \\
& \frac{\bar{F}\left(k_{1}\right)+(n-1) \bar{F}\left(k_{1} \sqrt{\frac{t_{S}+p Q}{t_{T}}}\right)}{n}=\frac{h_{b} Q}{D\left(\pi-c_{B S} i_{E} N\right)} \\
P & =\sqrt{\frac{1}{2 a_{2}}\left[2 a_{1}-(n-2) Q h_{v}+\frac{h_{b} \sigma Q}{D \sqrt{t_{S}+p Q}}\left\{k_{1}+\frac{\psi\left(k_{1}\right)}{\bar{F}\left(k_{1}\right)+(n-1) \bar{F}\left(k_{1} \sqrt{\left(t_{S}+p Q\right) / t_{T}}\right)}\right\}\right]} \\
& =\sqrt{\chi} .
\end{aligned}
$$

If $\chi<0$, then it is not possible to obtain a feasible solution of $P$ from equation (5.8). In that case, $P=P_{\min }$ as considered by Glock [17] and also

$$
P=\operatorname{Max}\left[P_{\min }, \operatorname{Min}\left[P_{\max }, \sqrt{\chi}\right]\right] .
$$

From expressions (5.5)-(5.8), it is clearly noted that the values of $Q, \widetilde{c_{S}}, k_{1}$, and $P$ are inextricably related with one another. Therefore, an iterative solution procedure is adopted to find the optimal results, and it is stated in "Solution Algorithm" by including the restriction $0<\widetilde{c_{S}} \leq c_{S}$.

\section{Solution Algorithm}

Step 1 . Set $n=1$.

Step 2. For given $t_{S} \in\left[t_{S, i}, t_{S, i-1}\right], i=1,2,3, \ldots, m$ perform Steps (2.1) to (2.9).

Step 2.1. Set $\widetilde{c_{S, i 1}}=0, \sigma_{i 1}=0$, and $P_{i 1}=\left[\sqrt{a_{1} / a_{2}}\right]$, where $[x]$ is the nearest integer to $x$.

Step 2.2. Substitute $P_{i 1}$ in equation (5.5) and obtain $Q_{i 1}$.

Step 2.3. Utilize $Q_{i 1}$ in equation (5.6) and calculate $\widetilde{c_{S, i 1}}$.

Step 2.4. Find $k_{i 1}$ and $k_{i 2}$ from equations (5.7) and (4.11) respectively with the help of normal table. Evaluate $\psi\left(k_{i 1}\right)$ from equation (4.9).

Step 2.5. Compute $P_{i 1}$ from (5.8). If $\chi<0$, set $P_{i 1}=P_{\min }$.

Step 2.6. Repeat Steps 2.2-2.5 until no changes are observed. Denote these unchanged values by $\left(Q_{i}, \widetilde{c_{S, i}}, k_{i}, P_{i}\right)$.

Step 2.7. If $\widetilde{c_{S, i}}<c_{S}$, then the solution is optimal and is denoted by $\left(Q_{i}^{*},{\widetilde{c_{S, i}}}^{*}, k_{i}^{*}, P_{i}^{*}\right)$.

Step 2.8. If $\widetilde{c_{S, i}} \geq c_{S}$, then set $\widetilde{c_{S, i}}=c_{S}$ and repeat Steps 2.2-2.7.

Step 2.9. Evaluate $\operatorname{EIC}\left(Q_{i}^{*}, \widetilde{c_{S, i}}{ }^{*}, k_{i}^{*}, P_{i}^{*}, t_{S, i}, n\right)$ from equation (4.12).

Step 3. If $\operatorname{EIC}\left(Q_{i}^{*}, \widetilde{c_{S, i}}{ }^{*}, k_{i}^{*}, P_{i}^{*}, t_{S, i}^{*}, n\right)=\operatorname{Min}\left[\operatorname{EIC}\left(Q_{i}^{*}, \widetilde{c_{S, i}}{ }^{*}, k_{i}^{*}, P_{i}^{*}, t_{S, i}, n\right)\right]$, then the optimal result will be $\left(Q_{i}^{*},{\widetilde{c_{S, i}}}^{*}, k_{i}^{*}, L_{i}^{*}, n\right)$ for fixed $n$.

Step 4. Set $n=n+1$ and repeat Steps 2 and 3 to find $\operatorname{EIC~}\left(Q_{n}^{*}, \widetilde{c_{S, n}}{ }^{*}, k_{n}^{*}, P_{n}^{*}, t_{S, n}^{*}, n\right)$.

Step 5. If $\operatorname{EIC}\left(Q_{n}^{*},{\widetilde{c_{S, n}}}^{*}, k_{n}^{*}, P_{n}^{*}, t_{S, n}^{*}, n\right) \leq \operatorname{EIC}\left(Q_{n-1}^{*}, \widetilde{c_{S, n-1}}, k_{n-1}^{*}, P_{n-1}^{*}, t_{S, n-1}^{*}, n-1\right)$, then go to Step 4, otherwise go to Step 6 .

Step 6. Set $\operatorname{EIC}\left(Q_{n}^{*},{\widetilde{c_{S, n}}}^{*}, k_{n}^{*}, P_{n}^{*}, t_{S, n}^{*}, n\right) \leq \operatorname{EIC}\left(Q_{n-1}^{*},{\widetilde{c_{S, n-1}}}^{*}, k_{n-1}^{*}, P_{n-1}^{*}, t_{S, n-1}^{*}, n-1\right)$. Then $\left(Q_{n}^{*},{\widetilde{c_{S, n}}}^{*}, k_{n}^{*}, P_{n}^{*}, t_{S, n}^{*}, n^{*}\right)$ is the optimal solution. 
Although the results which are obtained by using the above solution technique are not global, they are local optimum, but the valuable outcomes help to show how setup cost control and trade-credit financing together with alternative measures of lead time reduction effect the integrated expected total cost of a vendor-buyer system. In inventory literature, many authors $[1,17,18]$ have taken similar solution technique to get local optimum results for optimization problems with a comparable (not necessarily convex) structure.

\subsection{Correction in Glock's [17] model}

The expressions for production rate $P$ and expected total cost ETC are wrongly written in the article of Glock [17]. The correct expressions for $P$ and ETC are as follows.

$$
\begin{aligned}
P= & \sqrt{\frac{1}{2 a_{2}}\left[\frac{\sigma h_{b} Q}{D \sqrt{t_{S}+p Q}}\left\{k_{1}+\frac{\psi\left(k_{1}\right)}{\bar{F}\left(k_{1}\right)+(n-1) \bar{F}\left(k_{1} \sqrt{\left(t_{S}+p Q\right) / t_{T}}\right)}\right\}+2 a_{1}-(n-2) Q h_{v}\right]} \\
\mathrm{EIC}= & \frac{D G(n)}{Q}+\frac{Q H(n, P)}{2}+h_{b} k_{1} \sigma \sqrt{t_{S}+p Q}+\frac{D}{n Q}\left(\pi \sigma\left(\sqrt{t_{S}+p Q} \psi\left(k_{1}\right)+(n-1) \sqrt{t_{T}} \psi\left(k_{2}\right)\right)+n R\left(t_{S}\right)\right) \\
& +D\left(\frac{a_{1}}{P}+a_{2} P\right)
\end{aligned}
$$

with $G(n)=\frac{c_{0}+c_{S}}{n}+c_{T}$ and $H(n, P)=h_{b}+h_{v}(n(1-D p)-1+2 D p)$.

\section{Numerical RESUlts, COMPARATIVE STUdy AND MANAGERIAL INSIGHTS}

In this section, the present model is illustrated with the help of a suitable numerical example, and the results are compared with the results of Glock [17]. The managerial insights of the study are also discussed in subsection 6.3 .

\subsection{Numerical result}

The values of all the parameters of Glock's [17] model are considered together with some new parameters.

Example 1. The parameter values in suitable units are: $D=100$ units/time, $P_{\min }=150$ units $/$ time, $P_{\max }=700$ units $/$ time, $\sigma=5, \varepsilon=0.9, c_{S}=\$ 400 /$ setup, $c_{T}=\$ 100 /$ shipment, $c_{0}=\$ 150 /$ order, $h_{b}=\$ 2.5 /$ unit $/$ unit time, $h_{v}=\$ 1.7 /$ unit/unit time, $\pi=\$ 80 /$ unit, $a_{1}=\$ 300 /$ unit time, $a_{2}=\$ 1 / 300 /$ unit time, $u_{1}=0.05, U_{1}=0.1$, $u_{2}=0.08, U_{2}=0.15, u_{3}=0.04, U_{3}=0.1, c_{1}=10, c_{2}=30, c_{3}=70, \mu=0.03, A=2100, c_{B}=\$ 60 /$ unit, $c_{B S}=\$ 100 /$ unit, $i_{E}=i_{V}=0.2 / \$ /$ unit time, $i_{C}=0.6 / \$ /$ unit time, $N=2$.

By using the Solution Algorithm, the results found for Example 1 are recorded in Table 2, and the optimal solutions are summarized in Table 3 .

Table 3 shows that the optimal solutions for Example 1 are: $n^{*}=2, t_{S}^{*}=0.30, R\left(t_{S}^{*}\right)=\$ 0.5, Q^{*}=131$ units, ${\widetilde{c_{S}}}^{*}=\$ 165.06, k_{1}^{*}=1.54, P^{*}=309$ units/time, and the corresponding integrated expected total cost $\mathrm{EIC}^{*}=\$ 746.83$.

\section{Special case: Without setup cost reduction}

If the vendor does not invest for setup cost reduction, then the optimal results for that case are recorded in Table 4 which shows that $n^{*}=2, t_{S}^{*}=0.30, R\left(t_{S}^{*}\right)=\$ 0.5, Q^{*}=133$ units, $k_{1}^{*}=1.53, P^{*}=309$ units $/$ time, and $\mathrm{EIC}^{*}=\$ 779.92$. 
TABLE 2. The results of Example 1.

\begin{tabular}{llllllll}
\hline \hline$n$ & $t_{S}$ & $R\left(t_{S}\right)$ & $Q$ & $\widetilde{c_{S}}$ & $k_{1}$ & $P$ & EIC \\
\hline 1 & 0.35 & 0.0 & 134 & 84.42 & 1.38 & 359 & 769.62 \\
& $\mathbf{0 . 3 0}$ & $\mathbf{0 . 5}$ & $\mathbf{1 3 4}$ & $\mathbf{8 4 . 4 2}$ & $\mathbf{1 . 3 8}$ & $\mathbf{3 6 0}$ & $\mathbf{7 6 9 . 3 1}$ \\
& 0.23 & 2.6 & 134 & 84.42 & 1.38 & 360 & 769.87 \\
& 0.17 & 6.8 & 134 & 84.42 & 1.38 & 361 & 772.09 \\
\hline 2 & 0.35 & 0.0 & 131 & 165.06 & 1.52 & 308 & 747.05 \\
& $\mathbf{0 . 3 0}$ & $\mathbf{0 . 5}$ & $\mathbf{1 3 1}$ & $\mathbf{1 6 5 . 0 6}$ & $\mathbf{1 . 5 4}$ & $\mathbf{3 0 9}$ & $\mathbf{7 4 6 . 8 3}$ \\
& 0.23 & 2.6 & 131 & 165.06 & 1.56 & 309 & 747.68 \\
& 0.17 & 6.8 & 131 & 165.06 & 1.6 & 310 & 750.23 \\
\hline 3 & 0.35 & 0.0 & 128 & 241.92 & 1.59 & 249 & 772.97 \\
& $\mathbf{0 . 3 0}$ & $\mathbf{0 . 5}$ & $\mathbf{1 2 8}$ & $\mathbf{2 4 1 . 9 2}$ & $\mathbf{1 . 6 1}$ & $\mathbf{2 5 0}$ & $\mathbf{7 7 2 . 9 2}$ \\
& 0.23 & 2.6 & 128 & 241.92 & 1.64 & 251 & 773.95 \\
& 0.17 & 6.8 & 128 & 241.92 & 1.68 & 251 & 776.79 \\
\hline 4 & $\mathbf{0 . 3 5}$ & $\mathbf{0 . 0}$ & $\mathbf{1 2 7}$ & $\mathbf{3 2 0 . 0 4}$ & $\mathbf{1 . 6 6}$ & $\mathbf{1 7 2}$ & $\mathbf{8 0 2 . 3 4}$ \\
& 0.30 & 0.5 & 127 & 320.04 & 1.68 & 173 & 802.43 \\
& 0.23 & 2.6 & 127 & 320.04 & 1.72 & 174 & 803.73 \\
& 0.17 & 6.8 & 127 & 320.04 & 1.77 & 175 & 806.84 \\
\hline
\end{tabular}

TABLE 3. Optimal solutions for Example 1.

\begin{tabular}{llllllll}
\hline \hline$n$ & $t_{S}$ & $R\left(t_{S}\right)$ & $Q$ & $\widetilde{c_{S}}$ & $k_{1}$ & $P$ & EIC \\
\hline 1 & 0.30 & 0.5 & 134 & 84.42 & 1.38 & 360 & 769.31 \\
$\mathbf{2}^{*}$ & $\mathbf{0 . 3 0}^{*}$ & $\mathbf{0 . 5}^{*}$ & $\mathbf{1 3 1}^{*}$ & $\mathbf{1 6 5 . 0 6}^{*}$ & $\mathbf{1 . 5 4} \boldsymbol{*}$ & $\mathbf{3 0 9}^{*}$ & $\mathbf{7 4 6 . 8 3}^{*}$ \\
3 & 0.30 & 0.5 & 128 & 241.92 & 1.61 & 250 & 772.92 \\
4 & 0.35 & 0.0 & 127 & 320.04 & 1.66 & 172 & 802.34 \\
\hline
\end{tabular}

Notes. * Optimal result.

TABLE 4. Optimal solutions for the Special case.

\begin{tabular}{lllllll}
\hline \hline$n$ & $t_{S}$ & $R\left(t_{S}\right)$ & $Q$ & $k_{1}$ & $P$ & EIC \\
\hline 2 & 0.30 & 0.5 & 133 & 1.53 & 309 & 779.92 \\
\hline
\end{tabular}

\section{Discussion}

- Table 3 shows that the optimum value of integrated expected total cost for Example 1 is minimum for $n=2$ and it is $\mathrm{EIC}=\$ 746.83$. For $n=1$, EIC $=\$ 769.31$ which is greater than EIC for $n=2$. It means a single-setup-multi-delivery (SSMD) policy is more effective towards the reduction of integrated expected total cost than a single-setup-single-delivery (SSSD) policy. Again, if $n>2$, then though the holding cost of the vendor is reduced; but the transportation cost of the buyer is increased. As a result, the integrated expected total cost of the system increases.

- For a given setup and transportation time $\left(t_{S}\right)$, the production rate of the vendor decreases with an increase in $n$ (see Tab. 3). Therefore, the production run time increases and hence the lead time increases. Consequently, shortages during lead time demand increase, which increase the backordering cost as well as the EIC.

- From Table 3, it is observed that for a fixed setup and transportation time $\left(t_{S}\right)$, the order lot size decreases with the increase in the number of deliveries. So, the EIC reduces to some extent. 
TABLE 5. Comparison between the proposed model and the Special case.

\begin{tabular}{lll}
\hline \hline$n$ & $\begin{array}{l}\text { Proposed model (with setup cost } \\
\text { reduction) } \mathrm{EIC}^{*}(\$)\end{array}$ & $\begin{array}{l}\text { Special case (without setup cost } \\
\text { reduction) } \mathrm{EIC}^{*}(\$)\end{array}$ \\
\hline 2 & 746.83 & 779.92 \\
\hline
\end{tabular}

TABLE 6. Comparison between the optimal results of Glock's [17] and the present model.

\begin{tabular}{|c|c|c|c|c|c|}
\hline & $n$ & $t_{S}$ & $P$ & $Q$ & $\mathrm{ETC} / \mathrm{EIC}$ \\
\hline Glock's [17] model (after correction) & 4 & 0.30 & 216 & 88 & 765 \\
\hline Present model & 2 & 0.30 & 309 & 131 & 746 \\
\hline Savings $(\%)$ & \multicolumn{5}{|c|}{2.48} \\
\hline
\end{tabular}

- The setup cost $\left(\widetilde{c_{S}}\right)$ is directly proportional to the number of deliveries $(n)$ (see Eq. $(5.6)$ ). Therefore, it is noted in Table 3 that the setup cost increases with the increase in $n$ and hence the integrated expected total cost also increases.

- From Table 5, it is clear that an investment for setup cost reduction significantly reduces the integrated expected total cost.

Thus, among all the optimal solutions for Example 1 which are recorded in Table 3, the bold and stared faced optimal results give the minimum value of the integrated expected total cost.

\subsection{Comparative study}

In this subsection, a comparison has been made between the optimal results of Glock's [17] model (after correcting the expressions see Sect. 5.1) and the present model. The comparison is shown in a tabular form in Table 6.

It is clear from Table 6 that the present model can save a significant amount of money than Glock's [17] model. It saves $2.48 \%$ of money than Glock's [17] model. It seems that the introduction of setup cost reduction and trade-credit financing in Glock's [17] model presents a more cost reduced integrated supply chain system.

\subsection{Managerial insights}

The managerial insights of this study are as follows.

- Generally, waiting for a long time to get service has made customers impatient and sometimes it becomes a cause of lost sales. To avoid such loss sales, lead time reduction is one of the effective strategies. An introduction of lead time crashing cost has been a common practice to reduce lead time from the last few decades. In inventory literature, a few researchers are found to focus on some other ways to control lead time. The present paper has suggested some alternative ways of reducing lead time and these ways are reducing setup time, production time and transportation time. With the help of the suggested strategies, the manager of an industry may take a decision that which portion (s) of time is feasible for them to reduce.

- Every company has to bear a setup cost. Sometimes, it is very high, especially, for a long-time production process. An investment policy to reduce this setup cost is suggested in this paper which may help a manufacturing company to reduce their setup as well as the total cost.

- In the manufacturing process, the production rate is a very important factor. A higher production rate may generate defectives, on the other hand a lower production rate increases production run time and hence the lead time. Therefore, it is recommended to the managers to control the production rate within an upper and lower limit of production rate, so that they can control the lead time as well as the generation of defectives. 
- Usually, every firm/industry maintains a safety stock to avoid shortages. They decide the optimum reorder point based on a single safety factor. But if the length of lead time is too large, then there is a possibility to face large amount of shortages during the lead time. This study has considered a second safety factor to reduce the possibility of the occurrence of huge shortages. Although, two safety factors and lead time reduction strategies are considered, but still there is a chance of occurrence of shortages due to stochastic lead time demand. It is recommended to the industrial managers that if possible, keep double safety stocks to avoid shortages.

- Trade credit is a useful strategy to increase the profit and maintain goodwill with the buyers. This strategy encourages the buyer to order more. As a result, the sales of the products are increased and the goodwill between the producer and buyer is also increased. Therefore, it is suggested to the managers of the companies to offer a credit period to the buyers for payment.

\section{Conclusion}

Setup cost reduction and trade-credit financing are the two effective strategies that help to reduce the total cost of a production-inventory system as well as a supply chain system. The author has extended the work of Glock [17] by introducing these two strategies. A correction in the expression of production rate and expected total cost in Glock's [17] model is performed. An iterative solution algorithm is designed to achieve the optimal solutions.

In addition, the present model and the corrected model of Glock [17] have been compared with the help of numerical results. The comparison table (see Tab. 6) shows that the present model can save more money than the model discussed by Glock [17]. It means that the joint effect of lead time and setup cost control together with trade-credit financing help in the significant reduction of the integrated expected total cost. As far as the authors' knowledge go, such type of model has yet not been explored in inventory as well as supply chain literature. The authors expect that this study may help a firm or company to decide their optimal strategies.

One of the possible extensions of this proposed work can be the consideration of partial backlogging and lost sales. Other extensions may be the introduction of different demand patterns, multiple buyers, and multiple items.

Acknowledgements. The authors would like to express their gratitude to the editors and reviewers for their insightful comments to enhance the clarity of the article.

\section{REFERENCES}

[1] M. Ben-Daya and M. Hariga, Integrated single vendor single buyer model with stochastic demand and variable lead time. Int. J. Prod. Econ. 92 (2004) 75-80.

[2] M. Bhattacharyya and S.S. Sana, A mathematical model on eco-friendly manufacturing system under probabilistic demand. RAIRO:OR 53 (2019) 1899-1913.

[3] L.H. Chen and F.S. Kang, Coordination between vendor and buyer considering trade credit and items of imperfect quality. Int. J. Prod. Econ. 123 (2010) 52-61.

[4] K.J. Chung and L.E. Cardenas-Barron, The simplified solution procedure for deteriorating items under stock-dependent demand and two-level trade credit in the supply chain management. Appl. Math. Model. 37 (2013) 4653-4660.

[5] M. Das Roy, An EPQ model with variable production rate and markdown policy for stock and sales price sensitive demand with deterioration. Int. J. Eng. Sc. Math. 7 (2018) 260-268.

[6] M. Das Roy, A nonlinear EOQ model for time-dependent demand, deterioration, shortages with inflation. Int. J. Manage. Technol. Eng. 8 (2018) 1574-1584.

[7] M. Das Roy, Integrated supply chain model with setup cost reduction, exponential lead time crashing cost, rework and uncertain demand. Int. J. Res. Eng. Appl. Manage. 5 (2019) 752-757.

[8] M. Das Roy, Combine effect of quality, setup and ordering cost control in a three-stage multi-item supply chain model with transportation discounts. Int. J. Anal. Exp. Mod. Anal. 12 (2020) 470-479.

[9] M. Das Roy, Lead-time dependent ordering cost reduction and trade-credit: A supply chain model with stochastic demand and rework. Int. J. Rec. Tech. Eng. 8 (2020) 1-5.

[10] M. Das Roy and S. Sana, Random sales price-sensitive stochastic demand: An imperfect production model with free repair warranty. J. Adv. Manage. Res. 14 (2017) 408-424. 
[11] M. Das Roy, S. Sana and K. Chaudhuri, A stochastic EPLS model with random price sensitive demand. Int. J. Manage. Sci. Eng. Manage. 5 (2010) 465-472.

[12] M. Das Roy, S. Sana and K. Chaudhuri, An economic order quantity model of imperfect quality items with partial backlogging. Int. J. Syst. Sci. 42 (2011) 1409-1419.

[13] M. Das Roy, S. Sana and K. Chaudhuri, An optimal shipment strategy for imperfect items in a stock-out situation. Math. Comput. Model. 54 (2011) 2528-2543.

[14] M. Das Roy, S. Sana and K. Chaudhuri, An integrated producer-buyer relationship in the environment of EMQ and JIT production systems. Int. J. Prod. Res. 50 (2012) 5597-5614.

[15] M. Das Roy, S. Sana and K. Chaudhuri, An economic production lot size model for defective items with stochastic demand, backlogging and rework. IMA J. Manage. Math. 25 (2014) 159-183.

[16] B.K. Dey, S. Pareek, M. Tayyab and B. Sarkar, Autonomation policy to control work-in-process inventory in a smart production system. To appear in: Int. J. Prod. Res. (2020). DOI: 10.1080/00207543.2020.1722325.

[17] C.H. Glock, Lead time reduction strategies in a single-vendor-single-buyer integrated inventory model with lot size-dependent lead times and stochastic demand. Int. J. Prod. Econ. 136 (2012) 37-44.

[18] Y.C. Hsiao, A note on integrated single vendor single buyer model with stochastic demand and variable lead time. Int. J. Prod. Econ. 114 (2008) 294-297.

[19] C.K. Huang, D.M. Tsai, J.C. Wu and K.J. Chung, An optimal integrated vendor-buyer inventory policy under conditions of order-processing time reduction and permissible delay in payments. Int. J. Prod. Econ. 128 (2010) 445-451.

[20] M.Y. Jaber and I.H. Osman, Coordinating a two-level supply chain with delay in payments and profit sharing. Comput. Ind. Eng. 50 (2006) 385-400.

[21] U.S. Karmarker, Lot sizes, lead times and in-process inventories. Manage. Sci. 33 (1987) 409-418.

[22] J.S. Kim and W.C. Benton, Lot size dependent lead times in a Q, R inventory system. Int. J. Prod. Res. 33 (1995) 41-58.

[23] S.J. Kim and B. Sarkar, Supply chain model with stochastic lead time, trade-credit financing, and transportation discount. To appear in: Math. Prob. Eng. 2017 (2017) 6465912.

[24] A. Khanna, P. Gautam, B. Sarkar and C.K. Jaggi, Integrated vendor-buyer strategies for imperfect production systems with maintenance and warranty policy. RAIRO:OR $\mathbf{5 4}(2020) 435-450$.

[25] M. Khouja and A. Mehrez, Economic production lot size model with variable production rate and imperfect quality. J. Oper. Res. Soc. 45 (1994) 1405-1417.

[26] M. Lashgari, A.A. Taleizadeh and S.S. Sana, An inventory control problem for deteriorating items with back-ordering and financial considerations under two levels of trade credit linked to order quantity. J. Ind. Manage. Opt. 12 (2016) $1091-1119$.

[27] J.Y. Lee, R.K. Cho and S.K. Paik, Supply chain coordination in vendor-managed inventory systems with stockout-cost sharing under limited storage capacity. Eur. J. Oper. Res. 248 (2016) 95-106.

[28] Y. Li, X. Xu, X. Zhao, J.H.Y. Yeung and F. Ye, Supply chain coordination with controllable lead time and asymmetric information. Eur. J. Oper. Res. 217 (2012) 108-119.

[29] C.J. Liao and C.H. Shyu, An analytical determination of lead time with normal demand. Int. J.Oper. Prod. Manage. 11 (1991) $72-78$.

[30] Y.J. Lin, An integrated vendor-buyer inventory model with backorder price discount and effective investment to reduce ordering cost. Comput. Ind. Eng. 56 (2009) 1597-1606.

[31] D.R. Mahapatra, S. Panda and S.S. Sana, Multi-choice and stochastic programming for transportation problem involved in supply of foods and medicines to hospitals with consideration of logistic distribution. RAIRO:OR 54 (2020) 1119-1132.

[32] M.K. Maiti and M. Maiti, Two-storage inventory model with lot-size dependent fuzzy lead-time under possibility constraints via genetic algorithm. Eur. J.Oper. Res. 179 (2007) 352-371.

[33] A.I. Malika and B. Sarkar, Disruption management in a constrained multi-product imperfect production system. J. Manuf. Sys. 56 (2020) 227-240.

[34] L.Y. Ouyang and H.C. Chang, Lot size reorder point inventory model with controllable lead time and set-up cost. Int. J. Sys. Sci. 33 (2002) 635-642.

[35] B. Pal, S.S. Sana and K. Chaudhuri, Two-echelon competitive integrated supply chain model with price and credit period dependent demand. Int. J. Syst. Sci. 47 (2016) 995-1007.

[36] J.C.H. Pan and M.C. Lo, The learning effect on setup cost reduction for mixture inventory models with variable lead time. Asian Pac. J. Oper. Res. 25 (2008) 513-529.

[37] E. Porteus, Optimal lot sizing, process quality improvement and setup cost reduction. Opers. Res. 34 (1986) $137-144$.

[38] B. Sarkar, Mathematical and analytical approach for the management of defective items in a multi-stage production system. J. Clean. Prod. 218 (2019) 896-919.

[39] B. Sarkar and I. Moon, Improved quality, setup cost reduction, and variable backorder costs in an imperfect production process. Int. J. Prod. Econ. 155 (2014) 204-213.

[40] B. Sarkar and M. Sarkar, How does an industry reduce waste and consumed energy within a multi-stage smart sustainable biofuel production system? J. Clean. Prod. 262 (2020) 121-200.

[41] B. Sarkar, R. Guchhait, M. Sarkar and L.E. Cardenas-Barron, How does an industry manage the optimum cash flow within a smart production system with the carbon footprint and carbon emission under logistics framework? Int. J. Prod. Econ. 213 (2019) 243-257.

[42] B. Sarkar, R. Guchhait, M. Sarkar, S. Pareek and N. Kim, Impact of safety factors and setup time reduction in a two-echelon supply chain management. Robot. Comput.-Integ. Manuf. 55 (2019) 250-258. 
[43] B.R. Sarker and E.R. Coates, Manufacturing setup cost reduction under variable lead times and finite opportunities for investment. Int. J. Prod. Econ. 49 (1997) 237-247.

[44] N. Saxena, S.R. Singh and S.S. Sana, A green supply chain model of vendor and buyer for remanufacturing. RAIRO: OR 51 (2017) 1133-1150.

[45] N. Saxena, B. Sarkar and S.R. Singh, Selection of remanufacturing/production cycles with an alternative market: a perspective on waste management. J. Clean. Prod. 245 (2020) 118935.

[46] M. Tayyab, J. Jemai, H. Lim and B. Sarkar, A sustainable development framework for a cleaner multi-item multi-stage textile production system with a process improvement initiative. J. Clean. Prod. 246 (2020) 119055.

[47] S. Tiwari, S.S. Sana and S. Sarkar, Joint economic lot sizing model with stochastic demand and controllable lead-time by reducing ordering cost and setup cost. Rev. Real Acad. Ciencias Exactas Físicas Nat. Ser. 112 (2018) $1075-1099$.

[48] R. Uthayakumar and S. Priyan, Permissible delay in payments in the two-echelon inventory system with controllable setup cost and lead time under service level constraint. Int. J. Inf. Manage. Sci. 24 (2013) 193-211.

[49] R. Udayakumar, K.V. Geetha and S.S. Sana, Economic ordering policy for non-instantaneous deteriorating items with price and advertisement dependent demand and permissible delay in payment under inflation. To appear in: Math. Meth. Appl. Sci. (2020) DOI: $10.1002 / \mathrm{mma} .6594$.

[50] H.M. Wee, J.F. Jong and J.C. Jiang, A note on a single-vendor and multiple buyers production-inventory policy for a deteriorating item. Eur. J. Oper. Res. 180 (2007) 1130-1134.

[51] J.S. Yang and J.C.H. Pan, Just-in-time purchasing: an integrated inventory model involving deterministic variable lead time and quality improvement investment. Int. J. Prod. Res. 42 (2004) 853-863. 